\title{
CASE STUDY ON THE SPATIAL DEVELOPMENT IMPACT ASSESSMENT TOOL APPLIED IN THE SPATIAL DEVELOPMENT ENVIRONMENTAL SECURITY ASSESSMENT
}

The paper deals with the spatial development environmental security assessment employing the Spatial Development Impact Assessment tool and the geographical information systems. The first part includes a more detailed description of the Spatial Development Impact Assessment tool and ESRI - ArcInfo, which were the basis for elaborating the case study. The case study is presented in the second part of the paper, which includes the spatial development environmental security assessment for a fictitious hazardous waste incineration plant located in the zone of Moravian-Silesian region of the Czech Republic. The acquired outcomes are presented in the final part of the paper together with the proposed measures to be taken in order to reduce the potential risk of intended spatial development.

\section{Introduction}

At present there are a number of anthropogenic phenomena having the negative impacts on population. Spatial development causes number of risks [1] which may have negative impacts on balanced relations among spatial conditions and the environment, economic development and integrity of communities of population, i.e. on the sustainable development of territory $[2,3]$. Therefore one of the prerequisites of spatial development is the continuous provision of security, i.e. the spatial development environmental security [4].

The Spatial Development Impact Assessment [5] tool has been developed for the above mentioned purpose. The aim of the application is to realistically assess the potential hazard to the environment resulting from spatial development. The tool was developed in compliance with the national legal regulations of the Czech Republic, which makes the impact assessment process acceptable both from technological and legislative aspects.

\section{1. aterials and Methods}

The following chapter includes the most significant materials and methods, which were the basis for the presented case study on the Spatial Development Impact Assessment Tool Applied in the Spatial Development Environmental Security Assessment.

\subsection{Spatial Development Impact Assessment}

Spatial Development Impact Assessment tool for assessing the spatial development environmental security is based on the principle of semi-quantitative assessment of potential negative aspects of spatial development and the areas of their possible impacts. The key part of the tool is the Assessment Process Algorithm, which is based on integrated approach and stems from the algorithms of the Fire \& Explosion Index method [6] and the Hazard \& Impact Index method [7]. The assessment process algorithm defines basic relations among individual elements of the process, which may be divided into two basic groups: 1) the Hazards Group, which includes individual negative aspects of spatial development [8]; and 2) the Assets Group, which includes individual environmental elements. The algorithm itself consists of individual steps which result in determining the level of potential risk that the environment will be damaged due to intended spatial development (see Fig. 1).

The Catalogue of Hazards and Assets Groups consisting of individual categories and elements is another significant part of the Spatial Development Security Assessment tool. The individual categories of both groups then include partial elements with corresponding index values respecting their levels of hazard (in case of hazards group) and vulnerabilities (in case of assets group). The classification of the Catalogue of Hazards and Assets Groups is shown in Fig. 2.

\footnotetext{
* David Rehak ${ }^{1}$, Pavel Hrdina ${ }^{1}$, Michail Senovsky ${ }^{1}$, Jiri Dvorak ${ }^{2}$

${ }^{1}$ Faculty of Safety Engineering, VSB - Technical University of Ostrava, Ostrava-Vyskovice, Czech Republic, E-mail: david.rehak@vsb.cz

${ }^{2}$ Faculty of Economics and Management, University of Defence, Brno, Czech Republic
} 


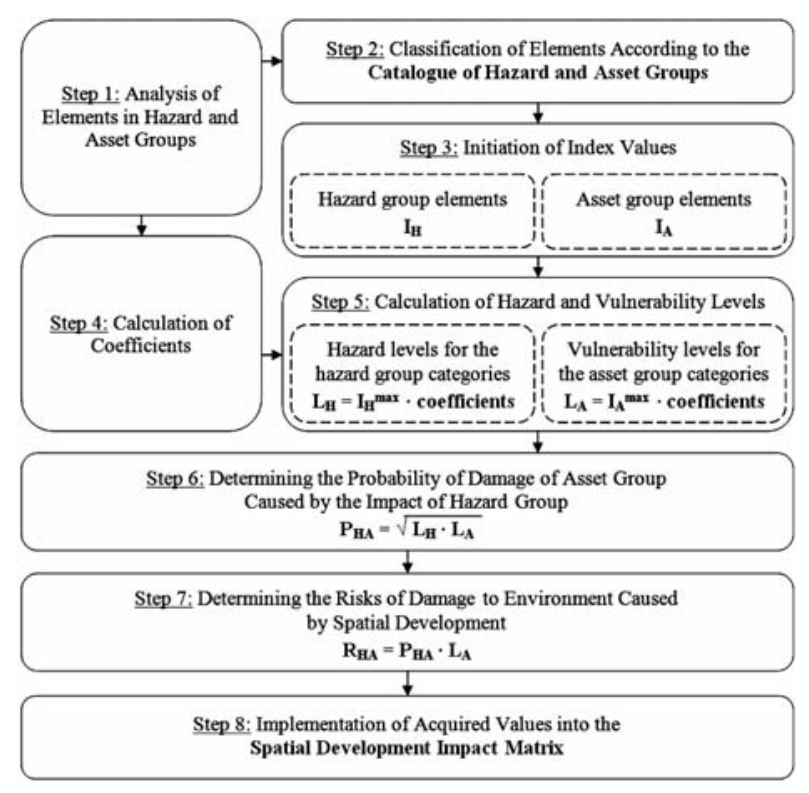

Fig. 1 Assessment Process Algorithm

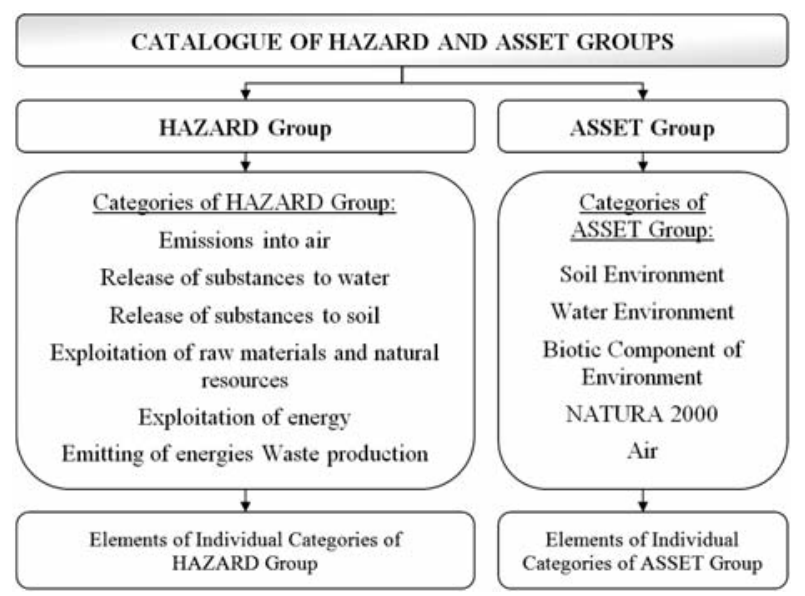

Fig. 2 Classification of the Catalogue of Hazards and Assets Groups

The outcome of the assessment process is the Matrix presenting the potential level of risk of environmental damage caused by intended spatial development (Spatial Development Impact Matrix). The risk is classified into 3 categories. The A Category indicates a low risk, which is assessed as acceptable, i.e. the intended spatial development may be fully brought into effect. The B Category indicates an increased risk, which will have to be reduced, i.e. the intended spatial development may be carried out with increased precautions. The $\mathrm{C}$ Category indicates a high risk, which is assessed as unacceptable, i.e. the intended spatial development would seriously damage the environment. Therefore its implementation is not recommended.

\subsection{ESRI - ArcInfo}

The general applicability of the geographic information system for the spatial development risk analysis is supported by the fact that there are a number of specific applications regarding e.g. the localization of the source of danger, the development of emergency scenarios, and various ways of assessing the combined risks in the territory [9]. The central program tool of the geographical information system (GIS), which will be used for developing the following case studies, is the product of ESRI - ArcInfo Company. It includes more than 200 data processing tools, the vector data analysis, full potential of data administration, the tools for generalizing the spatial data, and many others. It is the top set of applications for the Desktop GIS of the above mentioned company [10]. The mentioned software has been selected, because it is the most frequently used software in the Czech state administration authorities compared to other GIS solutions.

The Primary Basis of Geographical Data (ZABAGED - ZÁkladní BÁze GEografických Dat) serves as a key data source for display, modelling and calculation. It is a digitized topographic model of the Czech Republic derived from the map picture of the base map of the Czech Republic at a scale of 1:10 000 in the SJTSK grid system (see Fig. 3). The ZABAGED data are divided into planimetric and hypsometric data. The planimetric data include the objects classified into a number of classes (e.g. residences; economic and cultural facilities; roads; supply networks and pipelines). The hypsometric data include $2 \mathrm{~m}$ contour lines. The data were elaborated by the Czech Office for Surveying, Mapping and Cadastre [11].

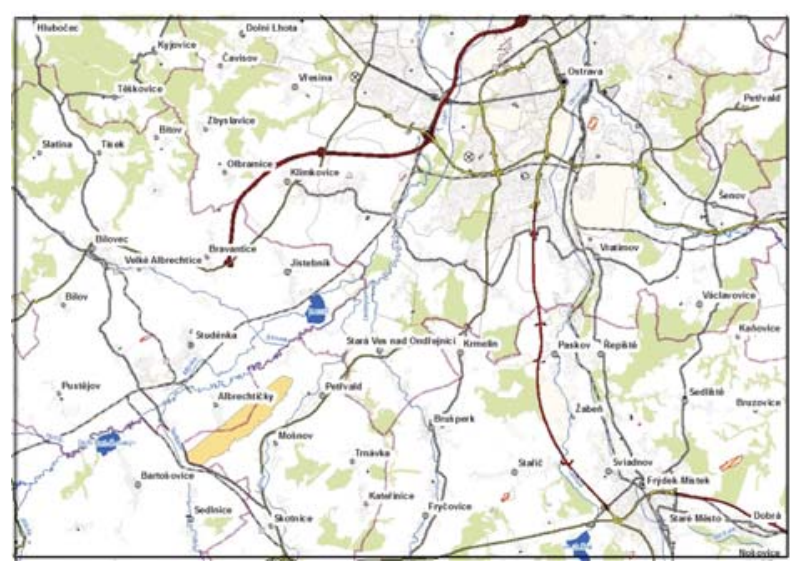

Fig. 3 The Primary Basis of Geographical Data (ZABAGED)

The Digital Basis of Water Management Data (DIBAVOD DIgitální BÁze VOdohospodářských Dat) is another data source. It is a working reference name for the proposed catalogue of objects as a thematic water management upgrade of ZABAGED. It is a reference geographic database developed primarily from the corresponding levels of ZABAGED and targeted at creating the thematic cartographic outcomes with the themes of water management and 
water protection. The administrator and provider of data is the T.G. Masaryk Water Research Institute in Brno. The data are provided free of charge [12]. Some data concerning the classification of protected landscape are taken from the Agency for Nature Conservation and Landscape Protection.

\section{Results of Case Study}

The following chapter is aimed at the case study on the Spatial Development Environmental Security Assessment for a fictitious hazardous waste incineration plant located in the zone of Moravian-Silesian region of the Czech Republic. The acquired outcomes are presented in the final part of the paper together with the proposed measures to be taken in order to reduce the potential risk of intended spatial development.

\subsection{Analysis of the Selected Element of Spatial Development: Description and Outcomes}

The element of spatial development, which has been selected for the case study, is a large capacity incineration plant of hazardous wastes. Its specification is as follows:

- Intended activities: treatment, storage and incineration of hazardous wastes;

- Capacity of incineration plant: 15 tons/day (1 rotary furnace);

- Received wastes: solid, pasty, liquid;

- Type of received waste: industrial hazardous wastes; medical and veterinary wastes;

- Waste dosing: grap, elevator, nozzle.

Based on the analysis of the above mentioned functional element of spatial development the particular negative environmental aspects have been assessed. Then the aspects have been inserted into the Catalogue of Hazards and Assets Groups and classified into individual categories (see Table 1).

The Outcomes of the Analysis of Spatial

Table 1 Development Element

\begin{tabular}{|l|l|}
\hline Category & Elements \\
\hline Emissions into air & $\begin{array}{l}\text { Occurrence of stationary sources of air pollution } \\
\text { - extra large incineration plants }\end{array}$ \\
\hline $\begin{array}{l}\text { Release of pollutants } \\
\text { into water }\end{array}$ & $\begin{array}{l}\text { Treatment of oil substances, extra hazardous } \\
\text { substances, radioactive emitters and radioactive } \\
\text { wastes }\end{array}$ \\
\hline $\begin{array}{l}\text { Release of pollutants } \\
\text { into soil }\end{array}$ & Treatment of extra hazardous substances \\
\cline { 2 - 2 } Emission of energies & Treatment of hazardous substances \\
\hline \multirow{2}{*}{ Waste production } & Production of municipal waste \\
\cline { 2 - 3 } & Production of inert waste \\
\hline
\end{tabular}

\subsection{Analysis of the Selected Area of Interest: Description and Outcomes}

The area of interest has been selected in order to verify the Spatial Development Impact Assessment tool and its possible interconnection with GIS. The area of interest is located in the Moravian-Silesian Region of the Czech Republic, east of the regional town of Ostrava, between the villages of Doubrava and Karviná (see Fig. 4).

The area is located in the close proximity of a primary road and a railway. Therefore it is easily accessible. Two zones have been created, $500 \mathrm{~m}$ and $1 \mathrm{~km}$ far from the facility, for better visualization of the facility located in the area. The zones only serve for easier interpretation of the ratio scale of the displayed area, otherwise it would be difficult to read it (the incineration plant itself covers the area of $160 \times 200 \mathrm{~m}$ ).

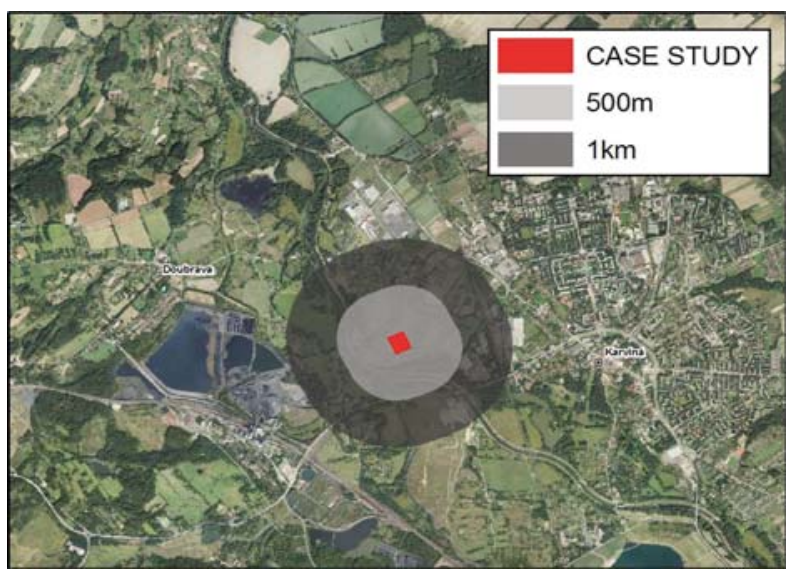

Fig. 4 The Area of Interest Displayed in Maps

The analysis of the area of interest has identified the occurrence of individual environmental elements, which may be damaged in the process of implementing the intended spatial development. Then the information has been inserted into the Catalogue of Hazards and Assets Groups and classified into individual categories (see Table 2).

\subsection{The Outcomes of the Spatial Development Environmental Security Assessment}

Upon inserting the acquired information into the Catalogue of Hazards and Assets Groups it was possible to assign appropriate index values (I) to the initiated elements. When creating the Spatial Development Impact Assessment tool the index values have been set by 20 expert assessors, who deal mainly with the issues of spatial planning, environmental protection and spatial development environmental impact assessment. The index values for the categories of the Assets Group are known to the users upon earmarking the area of interest into the GIS, as the GIS is interconnected with the database of the Catalogue of Hazards and Assets Groups. 
The Analysis of the Area of Interest: Outcomes

\begin{tabular}{|l|l|}
\hline Category, & Elements \\
\hline Soil Environment & Meadows and Pastures \\
\hline Water Environment & Water sources second level protection zones \\
\hline $\begin{array}{l}\text { Biotic Component } \\
\text { of Environment }\end{array}$ & Other Areas Without Special Protection \\
\hline NATURA 2000 & $\begin{array}{l}\text { Neither the area of European significance, nor } \\
\text { the bird area occur in the assessed area }\end{array}$ \\
\hline Air & $\begin{array}{l}\text { Air is highly polluted in the area (the average } \\
\text { annual immissions of PM10 exceed the } \\
\text { permitted immission limit values of } 40 \mu \mathrm{g} / \mathrm{m}^{3}\end{array}$ \\
\hline Cultural Heritage & $\begin{array}{l}\text { No element of cultural heritage occurs in the } \\
\text { assessed area }\end{array}$ \\
\hline
\end{tabular}

Then it was possible to calculate the coefficients by inserting the selected parameters into the pre-set formulas. The final coefficients consider variable parameters, which are e.g. range, frequency, and probability.

The acquired index values are then inserted into the formulas for calculating the levels of hazard in the categories of Hazards Group $\left(L_{H}\right)$ and the levels of vulnerability in the categories of Assets Group $\left(L_{A}\right)$. The level of each category has been calculated as the product of maximal index values of initiated elements classified in a particular category and the corresponding coefficients $\left(L=I^{\max } \cdot\right.$ coefficients $)$.

The next step was aimed at determining the probability $\left(P_{H A}\right)$ of damage to the categories of Assets Group caused by the categories of Hazards Group. The probability of damage has been mathematically determined through goniometric mean of the hazards and vulnerabilities of the assessed categories $\left(P_{H A}=\sqrt{ } L_{H} \cdot L_{A}\right)$.

The final step in the assessment process was to determine the level of risk of potential damage to the environment caused by the intended spatial development $\left(R_{H A}\right)$. The calculation of such risk is based on general platforms $[13,14,15]$. The level of risk has then been determined as the product of vulnerability level of a particular category of Assets Group and the probability corresponding to the assessed categories of Hazards and Assets Groups $\left(R_{H A}=\right.$ $\left.L_{A} \cdot P_{H A}\right)$.

The outcomes of the spatial development environmental security assessment are presented in the Spatial Development Impact Matrix (see Fig. 5).

The final levels of risk of potential damage to the assessed environmental categories in the area of interest caused by the impact of the environmental aspects of intended element of spatial development are classified into the following 3 risk categories:

- The A Category $(0.1$ - 0.45) - The environmental aspects of spatial development in this category are of low potential risk of damage to the environment in the assessed area (risk is acceptable). Even highly hazardous elements may be located in the

\begin{tabular}{|c|c|c|c|c|c|c|}
\hline \multirow{2}{*}{\multicolumn{2}{|c|}{$\begin{array}{l}\text { SPATIAL DEVELOPMENT } \\
\text { IMPACT MATRIX }\end{array}$}} & \multicolumn{5}{|c|}{ Categories of Hazard Group } \\
\hline & & \multirow{2}{*}{$A_{\lambda}$} & \multirow{2}{*}{$\frac{A_{w}}{1,47}$} & \multirow{2}{*}{$\frac{A_{5}}{1.47}$} & \multirow[t]{2}{*}{$A_{E}$} & \multirow{2}{*}{$\frac{A_{P}}{1,09}$} \\
\hline \multirow{6}{*}{ 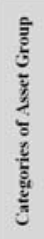 } & Soil Environment & & & & & \\
\hline & Water Environment & & 2,08 & 2.08 & & 1,61 \\
\hline & Biotic Component of Emironment & 0.55 & 0.62 & 0.62 & & 0,41 \\
\hline & NATURA 2000 & & & & & \\
\hline & Air & 2,18 & & & & \\
\hline & Cultural Heritage & & & & & \\
\hline
\end{tabular}

Fig. 5 Spatial Development Impact Matrix

Legend:

$A_{A}$ - Emissions into air

$A_{W}-$ Release of pollutants into water

$A_{S}-$ Release of pollutants into soil

$A_{E}-$ Emission of energies

$A_{P}-$ Production of wastes

Note: The crosshatched field indicates that the assessed categories either do not relate to each other or one of them is not assessed. Therefore the level of risk is not determined for such a relation.

area when following common safety measures. Achieving this category of risk is a necessary prerequisite for building the new industrial facilities.

- The B Category (0.46 - 1.75) - The environmental aspects of spatial development in this category are of increased potential risk of damage to the environment in the assessed area (it is necessary to reduce the risk). The planned spatial development may be carried out in the area. However, it is necessary to take an increased precaution into consideration in order not to damage the environment. In case the final level of risk is getting near the upper limit, it is recommended the planned spatial development to be re-analyzed and possibly re-planned and re-assessed.

- The C Category $(1.76-\infty)$ - The environmental aspects of spatial development in this category are of high potential risk of

Element of Spatial Development: INCINERATION FACILITY OF HAZARDOUS WASTES Case Study, Moravian-Silesian Region, 2010 Environmental Aspect: Release of Substances to Water

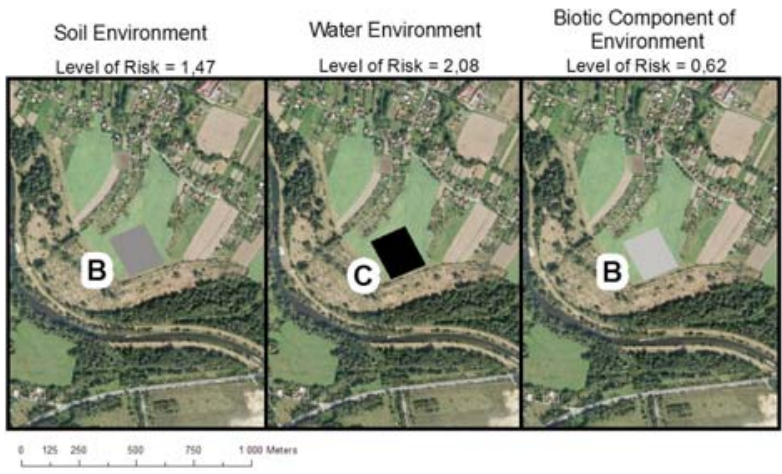

Fig. 6 Display of Assessment Outcomes in GIS 
damage to the environment in the assessed area (risk is unacceptable). This category indicates high probability that the planned spatial development will cause extensive and serious damage to the environment. It is recommended not only to look for another, less vulnerable area, but also thoroughly review the range and hazardousness of intended spatial development.

The display of outcomes of the environmental security assessment of the intended spatial development in the GIS is demonstrated on the environmental aspect of spatial development entitled "Release of pollutants into soil" (see Fig. 6).

\section{Conclusion}

The aim of the above presented case study was to assess the spatial development environmental security for a fictitious hazardous waste incineration plant located in the zone of Moravian-Silesian region of the Czech Republic. Based on the acquired outcomes it is possible to classify the potential risk of damage to the environment caused by spatial development into three categories.
The risk is acceptable (the A Category) in case of a potential negative impact of intended incineration plant on the biotic component of the environment - such a risk need not be further treated. The risk, which has to be reduced (the B Category), has been detected when analyzing the impacts of incineration plant on soil environment. The unacceptable risk (the $\mathrm{C}$ Category) has been detected when analyzing the impacts of incineration plant on water and air environment. Therefore it is not recommended to carry out the intended spatial development in the given area and either look for more suitable territory, or locate another element of spatial development into the area of interest, which is not of such a high risk for this particular area.

\section{Acknowledgments}

The paper has been elaborated within the Grant of the Czech Ministry of Interior filed under VD20062010A06 and entitled "The Research into New Principles and Methods within the Measures Aimed at the Protection of Population, Crisis Management and the Increased Readiness of Integrated Rescue System in Case of Possible Impacts of Chemical, Radiation and Nuclear Weapons and other Hazardous Substances“.

\section{References}

[1] SENOVSKY, M., SENOVSKY, P.: Critical Infrastructure Risks. Communications - Scientific Letters of the Universtiy of Zilina, 2008, No. 1, pp. 54-59. ISSN 1335-4205.

[2] MAIER, K.: Spatial Planning and Sustainable Development. $1^{\text {st }}$ Edition. Prague: ABF - Arch, 2008. 100 p. ISBN 978-80-86905-47-1.

[3] GATES, R.L., STOUT, F.: The Sustainable Urban Development Reader. $2^{\text {nd }}$ Edition. London \& New York: Routledge, 2004.512 p. ISBN 978-0-415-45382-0.

[4] RUZICKA, M., MIKLOS, L.: Landscape Ecological Planning (LANDEP) in the Process of Territorial Planning. Ekologia, 1982, No. 3, pp. 297-312. ISSN 1335-342X.

[5] REHAK, D.: Preventive Protection of Population, Technical Infrastructure and Environment against Negative Impacts of Spatial Development. Spektrum, 2010, No. 2, pp. 41-44. ISSN 1211-6920.

[6] Dow's Fire \& Explosion Index Hazard Classification Guide (FEI). $7^{\text {th }}$ Edition. USA, New York: American Institute of Chemical Engineers, 2005. 88 p. ISBN 978-0816906239.

[7] REHAK, D., DVORAK, J.: The Method of Preventive Military Training Environmental Impact Assessment (Hazard \& Impact Index). [Final Report on the progress made on the Grant project KJB606070701]. Czech Republic, Prague: Academy of Sciences of the Czech Republic, 2010. 64 p.

[8] ISO 14004:2004. Environmental Management Systems - General Guidelines on Principles, Systems and Support Techniques.

[9] HRDINA, P., KOTATKO, A., DOBES, P.: Territorial Unit Risk Analysis with the Use of Geographic Information Systems. Spektrum, 2010, No. 1, pp. 25-29. ISSN 1211-6920.

[10] ESRI - ArcInfo. [online]. ESRI. [cit. 2010-11-09]. Available from WWW: <http://www.esri.com/software/arcgis/arcinfo/index.html>.

[11] ZABAGED - The Primary Basis of Geographical Data. [online]. The Czech Office for Surveying, Mapping and Cadastre. [cit. 201010-23]. Available from WWW: <http://www.cuzk.cz/Dokument.aspx?PRARESKOD=998\&MENUID=0\&AKCE=DOC:30ZU_ZABAGED>.

[12] DIBAVOD - The Digital Basis of Water Management Data. [online]. T. G. Masaryk Water Research Institute. [cit. 2010-10-23]. Available from WWW: 〈http://www.vuv.cz/oddeleni-gis/index.php?id=27>.

[13] ISO 31000:2009. Risk Management - Principles and Guidelines.

[14] GRASSEOVA, M., DUBEC, R., REHAK, D. Analysis of the Enterprise at the Hands of Managers: 33 Most Frequently Applied Methods of the Strategic Management. $1^{\text {st }}$ Edition. Czech Republic, Brno: Computer Press, 2010. 325 p. ISBN 978-80-251-2621-9.

[15] DANIHELKA, P., POLEDNAK, P.: Risk Analysis - General Approach. Communications - Scientific Letters of the University of Zilina, 2008, No. 1, pp. 20-23. ISSN 1335-4205. 